\title{
The psychology of turning points in tennis
}

\author{
Ana Soares (POR) and Chris Harwood (GBR)
}

ITF Coaching and Sport Science Review 2017; 71 (25): 29 - 31

\begin{abstract}
The psychological strategies used by players to deal with these turning points will determine how effective players are in using these situations to their advantage. The purpose of this study was to investigate the concept of turning points and understand more clearly the strategies applied by elite players to deal with turning points during a tennis match. A series of semi-structured interviews was conducted with nine elite professional players from five different countries, followed by a thematic content analysis of the interviews. The analysis revealed four key themes: positive turning points situations, negative turning points situations, strategies to capitalise on positive turning points and strategies to cope with negative turning points. On a practical level, strategies are suggested that coaches and psychologists can use to help players managing turning points. This research was partially supported by an International Tennis Federation Sport Science Research Grant.
\end{abstract}

\author{
Key words: Psychology, \\ turning point situations, coping \\ methods \\ Received: 30 Sep 2016 \\ Accepted: 25 Feb 2017 \\ Corresponding author: \\ Ana Soares \\ Email: anadsoares@gmail.com
}

\section{INTRODUCTION}

Momentum is a frequently mentioned concept in the sporting community (Higham, 2000). Coaches, athletes and supporters perceive it and talk about it; however, from a scientific point of view, it remains an elusive concept (Moesch \& Apitzsch, 2012). Turning points are commonly associated with momentum and are defined, in the current research proposal, as situations in a match that affect the feelings of control a player has at a given moment.

Momentum is frequently divided into positive and negative momentum (Briki, Den Hartigh, Markman \& Gernigon, 2014). According to Briki and colleagues (2014), positive psychological momentum is experienced as an upward spiral, a period in which everything seems to go well. Negative psychological momentum is perceived as a downward spiral, where everything seems to go wrong.

Since the 1980 s, a growing body of research has examined the concept of psychological momentum. Different models of psychological momentum have been developed and partly corroborated. However, despite the increased knowledge about different aspects of momentum and the development of models that can be tested empirically, momentum still needs further investigation (Crust \& Nesti, 2006). In tennis, specifically, knowledge of how the players perceive turning points and what strategies they use to deal with them is limited. At the elite athlete level, this concept has not yet been investigated in any sport.

As such, in order to assist coaches, players and sport psychologists when planning psychological interventions, current research employed a qualitative method, consisting of semi-structured interviews that explored elite players' perspective of turning points and the strategies applied by these players to deal with turning points during a match.

\section{METHOD}

Participants

Nine male professional players or ex-players from five different countries, aged between 26 and 72 years $(M=44, S D=15)$, were interviewed. All participants had played in the main event of a Grand Slam and played for their country's Davis Cup. The highest ranked player interviewed was number seven in the world and the lowest ranked player was in the top 190. The median value of the best rankings was 48 .

\section{Procedure}

A series of in-depth semi-structured interviews was conducted. Interviews lasted between 29 and 88 minutes $(M=61, S D=$ 24). An inductive thematic analysis was used, which allowed the emerging themes to be closed linked to the data (Braun \& Clarke, 2006).

\section{RESULTS}

Data analysis resulted in two main categories related to experiences of turning points. These categories were turning point situations and managing turning points. These two categories were then divided into positive and negative turning points situations and strategies to cope with negative and to capitalise on positive turning points (see Figure 1).

The following sections highlight some of the categories mentioned in figure 1 , including quotations from the participants.

\section{Positive turning point situations}

Participants described several situations that they consider positive turning points. These situations were divided into two categories: directly related and not directly related to the scoring system.

One situation directly related to the scoring system mentioned by the participants was opting for a risky shot and winning the point when about to lose the match. As an example, participant A described, "The guy was serving. I was one set and 5-4 down. He was serving, and I closed my eyes on two down-the-line shots, and it went well, and after that I started playing well".

Negative turning point situations

The negative situations were also divided into those directly related and not directly related to the scoring system.

Situations that are not directly related to the scoring system are, for example, significant delays that stop the normal 
progression of the match, such as rain delays or medical timeout:

If I hadn't stopped for the rain, I would have beaten him 6-1, 60, 6-1 or 6-0. I mean, I was on a roll, and I think that for that guy, it was good to have time to think, and that's why the third set was completely different from the others (participant B).

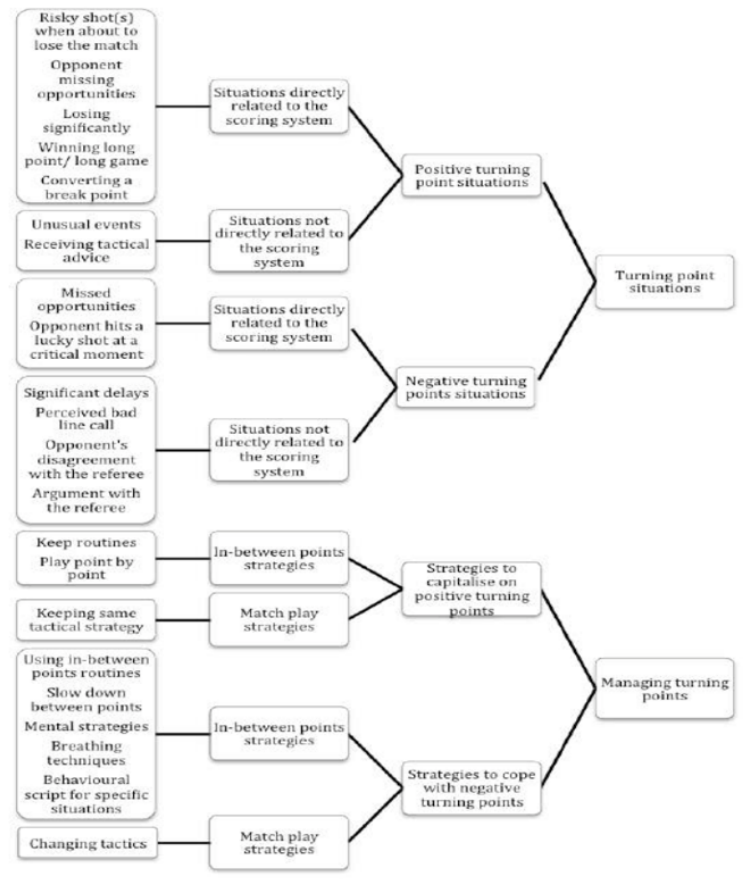

Figure 1. Analysis of turning point experiences.

Strategies to capitalise on with positive turning points

When dealing with a positive turning point, participants emphasised continuity: keeping to routines between points and keeping the same tactics that they used to get to the positive situation.

The strategies described can be divided into in-between points strategies and match play strategies. After a positive turning point, participants stated, "If things start to go well, I keep the same [in- between points] routine (...). It makes me stay more concentrated, focused on the match, and then I keep this routine, and I make the turning point [effect] last longer" (participant A).

\section{Strategies to cope with negative turning points}

When contemplating how a player can cope with a negative turning point, participants gave many examples of in-between points strategies and match play strategies.

Regarding in-between points strategies, players described going back to their routines after a negative turning point: "Usually, I turn to my rituals, like, I turn to the towel or ask the ball boy for the towel" (participant D). The same player mentioned that he would do this routine but "try to go a bit slower." Taking breaks, such as "asking for the trainer", "going to the toilet, taking time between points: that is, breaking his rhythm," (participant I) is a strategy that participants referred to as important after experiencing a negative turning point. When a player is faced with a situation that happens frequently and is consistently becoming a negative turning point, a player can develop an alternative, specific strategy to cope with it. For example, a player described that when the opponent went offcourt, he would also leave and made sure the opponent was coming back to the court first.

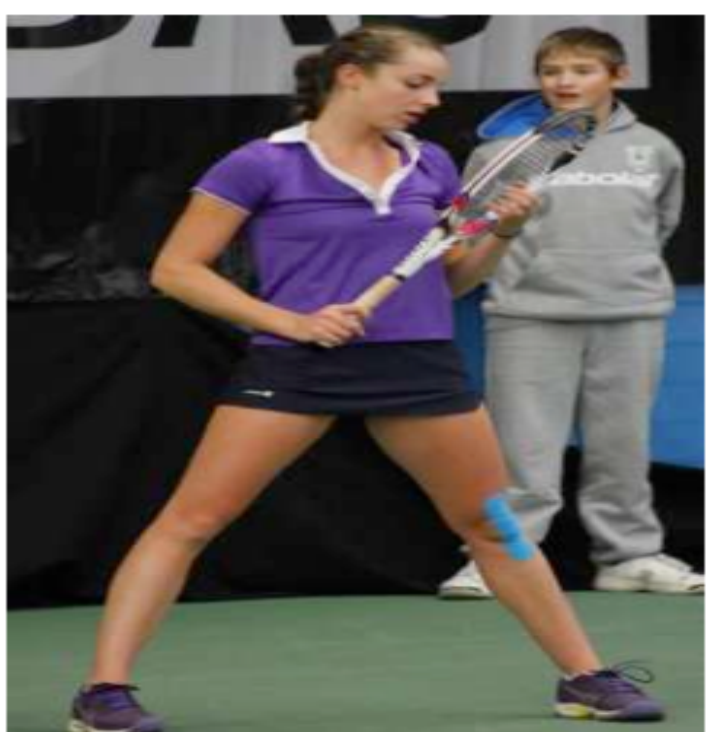

DISCUSSION AND PRACTICAL IMPLICATIONS

When describing how to manage turning points, players reinforced the idea of change when coping with negative turning points and the idea of continuity when capitalising on positive turning points. However, routines in-between points were mentioned as a strategy that should be used in both moments, which reinforces its importance as a fundamental psychological strategy in tennis (Mamassis \& Doganis, 2004). Regarding practical implications, the first topic that should be highlighted is the preparation for matches. This is important because there is probably potential for turning points in every match. According to a player:

Because of the way that tennis is played and scored, I honestly think that these moments are happening ... well, if it was a three set match, there's potential for them hundreds of times in a match because of how it works (participant E).

Therefore, players should be aware that potentially, one or more events during a match will represent an additional risk or a potential opportunity to change the control of the match.

From a psychological perspective, preparation for a match should include a combination of psychological strategies that should be developed outside the competition so that the players can apply such in matches. Such strategies can include routines, breathing exercises and specific scripts to deal with a particular situation (such as leaving the court when the opponent has left the court and returning after the opponent has returned). Each player should understand what kind of strategy or routine is useful for his/her particular case and apply it consistently throughout the match (in the case of routines) or whenever he/she feels that a situation might be a potential turning point.

\section{CONCLUSION}

Findings from this study suggest that players consider a variety of events in a match as turning points. According to the players, these situations can be seen as positive or negative and there is a range of strategies that can be used to deal with them. As such, this research provides applied implications that can be used with players, in order to help them to take advantage of positive turning points situations and adequately cope with negative turning points situations. However, the identification of a turning point seems to be an individual phenomenon and as such, different strategies should be adapted to the specific characteristics and needs of each player. 
REFERENCES

Braun, V., \& Clarke, V. (2006). Using thematic analysis in psychology. Qualitative Research in Psychology, 3, 77

101.https://doi.org/10.1191/1478088706qp063oa

Briki, W., Den Hartigh, R. J. R., Markman, K. D., \& Gernigon, C. (2014). How do supporters perceive positive and negative psychological momentum changes during a simulated cycling competition? Psychology of Sport and Exercise, 15(2), 216-221. doi:10.1016/j. psychsport.2013.11.006https://doi.org/10.1016/j. psychsport.2013.11.006

Crust, L., \& Nesti, M. (2006). A review of psychological momentum in sports: why qualitative research is needed, 8(1), 1-15. Retrieved from http://www.athleticinsight.com/Vol8lss1/Moment um.htm

Higham, A. (2000). Momentun: The hidden force in tennis. Oxford: Meyer and Meyer Sport.

Mamassis, G., \& Doganis, G. (2004) The Effects of a Mental Training Program on Juniors Pre-Competitive Anxiety, Self-Confidence, and Tennis Performance. Journal of Applied Sport Psychology, 16, 118-137. doi: 10.1080/10413200490437903

Moesch, K., \& Apitzsch, E. (2012). How Do Coaches Experience Psychological Momentum ? A Qualitative Study of
Female Elite Handball Teams. The Sport Psychologist, 26, 435-

453.https://doi.org/10.1123/tsp.26.3.435

RECOMMENDED ITF TENNIS ACADEMY CONTENT (CLICK BELOW)

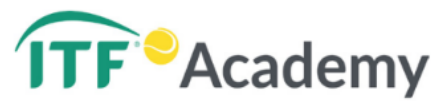

Copyright (c) Ana Soares and Chris Harwood 2017

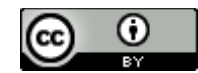

This text is under a Creative Commons BY 4.0 license

You are free to Share - copy and redistribute the material in any medium or format - and Adapt the content - remix, transform, and build upon the material for any purpose, even commercially under the following terms:

Attribution: You must give appropriate credit, provide a link to the license, and indicate if changes were made. You may do so in any reasonable manner, but not in any way that suggests the licensor endorses you or your use.

CCBY 4.0 license terms summary $\quad$ CCBY 4.0 license terms 